\title{
Effects of Age, Gender, and Menopausal Status on Small Dense Low-Density Lipoprotein Cholesterol and Low-Density Lipoprotein Cholesterol Fractions; JMS-II Cohort Study
}

Toshihide Izumida ( $\nabla_{\text {m07011ti@jichi.ac.jp ) }}$

Kanazawa Medical University Himi Municipal Hospital https://orcid.org/0000-0003-2703-2523

Yosikazu Nakamura

Jichi Mecical University

Yukihiro Sato

Kamiichi General Hospital

Shizukiyo Ishikawa

Jichi Medical University

Research

Keywords: sdLDL-C, sdLDL-C/LDL-C ratio, age, gender, menopause

Posted Date: June 11th, 2020

DOl: https://doi.org/10.21203/rs.3.rs-34566/v1

License: (c) (i) This work is licensed under a Creative Commons Attribution 4.0 International License.

Read Full License 


\section{Abstract}

\section{Background:}

Small dense low-density lipoprotein cholesterol (sdLDL-C) might be a better cardiovascular disease (CVD) indicator than low-density lipoprotein cholesterol (LDL-C); however, details regarding its epidemiology remain elusive. The present study aimed at evaluating the effect of age, gender, and menopausal status on sdLDL-C levels and sdLDL-C/LDL-C ratio in the Japanese population.

\section{Methods:}

We examined the baseline cross-sectional data from the Jichi Medical School-II Cohort Study, including 5,208 participants (2,397 men and 2,811 women). To assess age-related trends, the sdLDL-C and sdLDLC/LDL-C ratios were plotted against gender. We evaluated the effect of age and menopausal status using multiple linear regression analysis.

\section{Results:}

We observed that in men, the sdLDL-C levels and sdLDL-C/LDL-C ratio increased during younger adulthood, peaked at 50-54 years, and then decreased. In women, we observed relatively regular increasing trends of sdLDL-C level and sdLDL-C/LDL-C ratio until approximately 65 years, followed by a downward or pleated trend. The crossover of sdLDL-C levels for the genders occurred at 70-74 years, but we could not observe any sdLDL-C/LDL-C ratio crossover. Standardized sdLDL-C levels and sdLDLC/LDL-C ratio in 50-year old men, premenopausal women, and postmenopausal women were 26.6, 22.7, and $27.4 \mathrm{mg} / \mathrm{dL}$ and $0.24,0.15$, and 0.23 , respectively. The differences between premenopausal and postmenopausal women were significant $(P<0.001)$.

\section{Conclusions:}

sdLDL-C and sdLDL-C/LDL-C ratios show different distributions by age, gender, and menopausal status with trends different from other lipids. A subgroup-specific approach would be necessary to implement sdLDL-C for CVD prevention strategies, fully considering age-related trends, gender differences, and menopausal status.

\section{Introduction}

Although the association between hypercholesterolemia and cardiovascular disease (CVD) has been well established, total cholesterol (TC), low-density lipoprotein cholesterol (LDL-C), and non-high-density lipoprotein cholesterol (nonHDL-C) have not been good enough to predict risk stratification and we need the novel target. ${ }^{1-3}$

Small dense low-density lipoprotein cholesterol (sdLDL-C) shows increased penetration into the arterial wall by the small sizes and high susceptibility to oxidation and may be one of the leading causes of 
atherosclerosis. ${ }^{4}$ In fact, elevated sdLDL-C can be found in patients with metabolic syndrome, which have been found as highly atherogenic conditions without hypercholesterolemia. ${ }^{5}$ Current studies suggest that the sdLDL-C or sdLDL-C/LDL-C ratio might be the better factors for the prediction of CVD than total cholesterol or LDL-C in the general population or patients with CVD. ${ }^{6-9}$

However, almost all of the current analytical strategies might be not able to adjust accurately the interaction between age and sdLDL-C due to the association between the lipid factors and age, which might follow a curvilinear model. Few studies have evaluated how age is associated with SdLDL-C and sdLDL-C/LDL-C ratio over a wide age range and distinguished the effects of menopause and gender on sdLDL-C and sdLDL-C fraction from those of aging. ${ }^{10,11}$

Diet composition, which is affected by aging, has a significant effect on blood cholesterol and the absorption, synthesis, and metabolism per se of fat and lipoproteins change with age. ${ }^{12,13}$ Asian agerelated trends of traditional lipid profiles displayed roughly an increasing trend, followed by a decreasing one at the middle-aged stage. ${ }^{14,15}$ However, sdLDL-C has been regulated by more complex mechanisms than regulating traditional lipids and might be plateaued or increased even at the middle-aged by changed metabolic functions with aging influencing sdLDL-C synthesis. ${ }^{5,7,12,16,17}$

Furthermore, the detailed multiple mechanisms of metabolizing sdLDLs are unknown in the real-world, population-based setting and the age-related trend of sdLDL-C might be different from the sdLDL-C/LDL$C$ ratio. In other words, the ability to generate sdLDL-C from LDL-C might be different among each generation, gender, and menopausal status.

Therefore, we evaluated the effect of age, gender, and menopausal status on sdLDL-C and sdLDL-C/LDL$\mathrm{C}$ ratio in Japanese general population.

\section{Methods}

\section{Population}

This is a cross-sectional analysis of data from the Jichi Medical School (JMS)-II Cohort Study, which is a prospective, population-based cohort study aimed to evaluate the relationship between the risk factors of atherosclerosis and CVD in the Japanese general population. A total of 6,436 individuals participated in this study. Data were obtained from 13 rural districts in Japan, Shimotsuke, Kakara, Sue, Omori, Kamiichi, Wara, Takasu, Onabi, Nakatsu, Yame, Miwa, Ueno, and Saji areas, between April 2010 and December 2017. In each community, a local government office sent personal invitations for mass CVD screenings to all the subjects by mail. This study evaluated Japanese individuals who underwent the health screening that was conducted in accordance with the medical care system for the elderly and obtained informed consent for this study. We excluded individuals as follows: 1) taking lipid-lowering agents or antihyperglycemia agents $(n=1,073) ; 2)$ the use of hormone replacement therapy $(n=96)$; and 3$)$ the data such as age, gender status, menopausal status, and sdLDL-C were not available $(n=73)$. 


\section{Measurements}

Patients' height and weight were measured using a standardized method, with $0.1 \mathrm{~cm}, 0.1 \mathrm{~kg}$, and $0.1 \mathrm{~cm}$ units of measurement, respectively. Height was measured with stockinged feet. Weight was recorded with the subjects clothed. Body mass index (BMI) was calculated as weight $(\mathrm{kg}) /$ height $\left(\mathrm{m}^{2}\right)$. Blood samples were taken after overnight fasting. An external laboratory (SRL, Tokyo, Japan) measured total cholesterol (TC), triglycerides (TGs), LDL-C, high-density lipoprotein cholesterol (HDL-C), and sdLDL-C levels. TC was measured using a cholesterol dehydrogenase-ultraviolet method. TG was measured via an enzymatic method. LDL-C and HDL-C were measured by direct methods. The SdLDL-C level was directly and selectively measured using a commercial kit (sdLDL-EX from Denka Seiken, Tokyo, Japan). Serum lipid markers were measured by the standardized program proposed by the Clinical and Laboratory Standards Institute. The nonHDL-C was calculated by subtracting HDL-C from TC. Information about medical history, lifestyle, and menopausal status were obtained with a self-reported questionnaire. Questions about past or present illness were asked, and if present, whether the subjects took medicine or not was confirmed. Smoking status was classified as smoking, former smoking, or never-smoking. All the participants included in the present study provided written informed consent prior to inclusion, and this study was approved by the Institutional Review Board of Jichi Medical School (Tochigi, Japan, IRB No. G09-39 [G17-64 revised]).

\section{Statistical analysis}

Baseline characteristics were summarized as mean \pm standard deviation (SD) for normally distributed continuous variables and numbers and percentages for categorical variables. SdLDL-C and TG were highly skewed; these data were expressed as the median and interquartile range and transformed into natural logarithms before statistical analysis.

The one-way analysis of variance (ANOVA) was used for comparison among three groups, and differences were tested via post hoc pairwise comparison (Bonferroni). To explore the age-related trend in sdLDL-C and sdLDL-C/LDL-C ratio with age, geometric means or means and 95 percent confidence intervals for each variable in 5-year age ranges were derived and plotted against age range in each of the three groups.

Among the three groups, correlations between age and each parameter were assessed using multiple linear regression analysis. The agreement between the estimated sdLDL-C and SdLDL-C/LDL-C ratio and measured ones was assessed by Pearson's correlation coefficient. To evaluate the effect of menopausal status on sdLDL-C and sdLDL-C/LDL-C ratio, using the beta value of each variable from the analysis in the premenopausal and postmenopausal group, data were standardized to a nominal 50 years of menopausal age, never smoking and zero alcohol for participants with normal weight (BMI 18.5-22.0). All statistical analyses were performed using SPSS version 22 (IBM, Chicago, IL, USA), and statistical significance was defined as $\mathrm{P}<0.05$. 


\section{Results}

\section{Baseline characteristics}

After exclusions, 517 premenopausal women (mean age \pm SD, $45.1 \pm 4.2$ years), 2,294 postmenopausal women ( $66.5 \pm 8.8$ years) and 2,397 men (64.1 \pm 11.2 years) were analyzed. Demographic data for the three groups are shown in Table 1. Compared with men, premenopausal women had higher HDL-C and postmenopausal women had higher TC, LDL-C, HDL-C, and nonHDL-C. Compared with premenopausal women, postmenopausal women had higher fasting glucose, TC, LDL-C, TG, nonHDL-C, TC/LDL-C, sdLDL-C, and sdLDL-C/LDL-C. TC and LDL-C didn't differ between men and premenopausal women. 
Table 1

Baseline characteristics

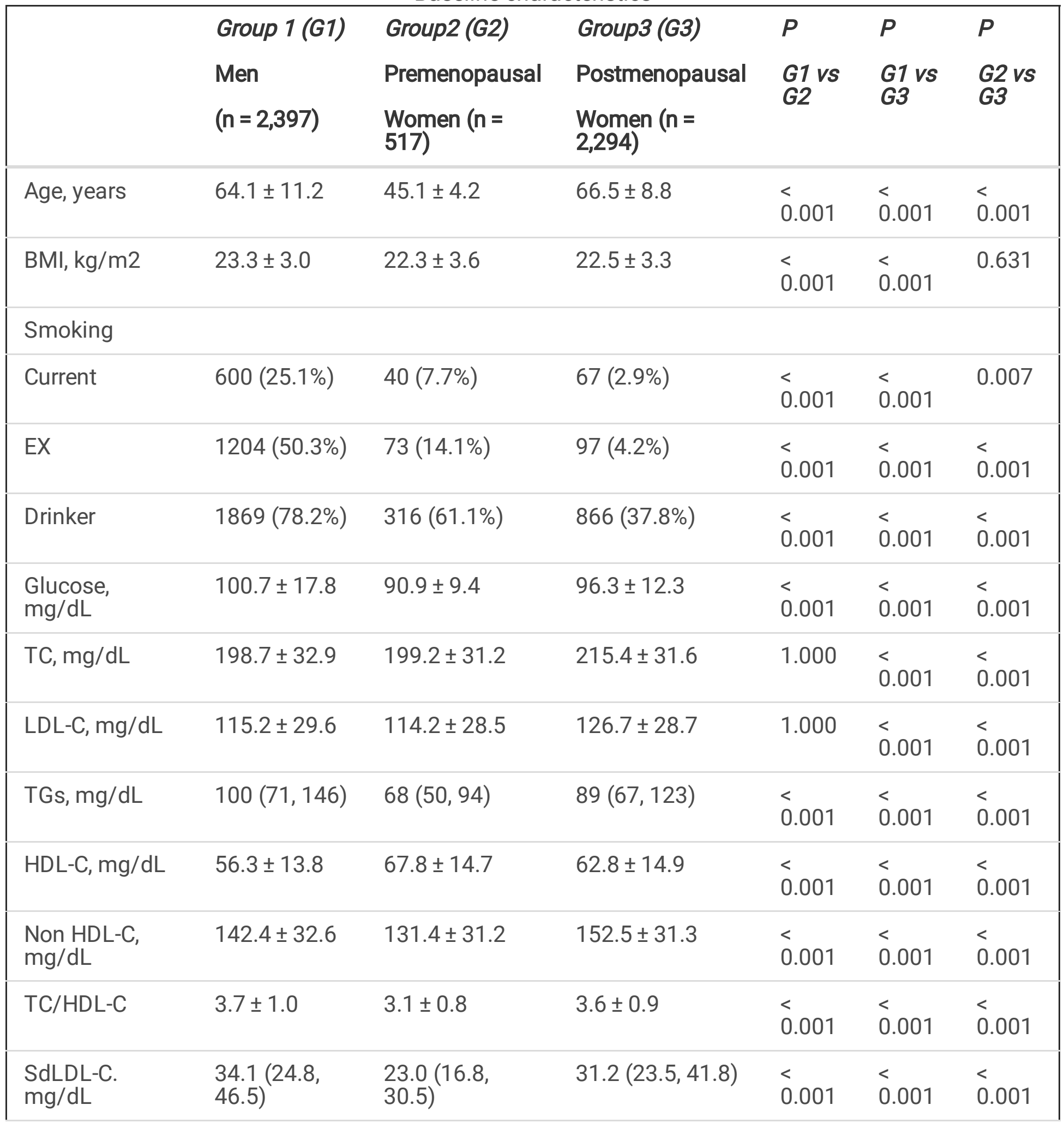

Data are expressed as mean \pm standard deviation (SD), \%, and median (25th percentile, 75th percentile). P-values were assessed in one-way analysis of variance (ANOVA) and post hoc pairwise comparison (Bonferroni). $\mathrm{BMI}=$ body mass index; $\mathrm{TC}=$ total cholesterol; $\mathrm{LDL}-\mathrm{C}=$ low-density lipoprotein cholesterol; TGs = triglycerides; $\mathrm{HDL}-\mathrm{C}=$ high-density lipoprotein cholesterol; non HDL-C = non high-density lipoprotein cholesterol; $s d L D L-C=$ small dense low-density lipoprotein cholesterol. 


\begin{tabular}{|c|c|c|c|c|c|c|}
\hline & \multirow{3}{*}{$\begin{array}{l}\text { Group } 1(G 1) \\
\text { Men } \\
(n=2,397)\end{array}$} & \multirow{3}{*}{$\begin{array}{l}\text { Group2 (G2) } \\
\text { Premenopausal } \\
\text { Women ( }= \\
517 \text { ) }\end{array}$} & \multirow{3}{*}{$\begin{array}{l}\text { Group3 (G3) } \\
\text { Postmenopausal } \\
\text { Women ( } \mathrm{n}= \\
2,294)\end{array}$} & \multirow{3}{*}{$\begin{array}{l}P \\
\text { G1 vs }\end{array}$} & \multirow{3}{*}{$\begin{array}{l}P \\
\text { G1 vs } \\
\text { G3 }\end{array}$} & \multirow{3}{*}{$\begin{array}{l}P \\
G 2 \text { vs } \\
\text { G3 }\end{array}$} \\
\hline & & & & & & \\
\hline & & & & & & \\
\hline $\begin{array}{l}\text { SdLDL-C/LDL- } \\
\mathrm{C}\end{array}$ & $0.32 \pm 0.14$ & $0.22 \pm 0.08$ & $0.29 \pm 0.12$ & $<.001$ & $\dot{0} 001$ & $\begin{array}{l}< \\
0.001\end{array}$ \\
\hline \multicolumn{7}{|c|}{$\begin{array}{l}\text { Data are expressed as mean } \pm \text { standard deviation }(\mathrm{SD}), \% \text {, and median }(25 \text { th percentile, } 75 \text { th } \\
\text { percentile). P-values were assessed in one-way analysis of variance }(A N O V A) \text { and post hoc pairwise } \\
\text { comparison (Bonferroni). BMI = body mass index; } T C=\text { total cholesterol; } L D L-C=\text { low-density } \\
\text { lipoprotein cholesterol; } T G s=\text { triglycerides; } \mathrm{HDL}-\mathrm{C}=\text { high-density lipoprotein cholesterol; non } \mathrm{HDL}-\mathrm{C}= \\
\text { non high-density lipoprotein cholesterol; } \text { sdLDL-C }=\text { small dense low-density lipoprotein cholesterol. }\end{array}$} \\
\hline
\end{tabular}

To assess the age-related trend in sdLDL-C levels, a 5-year age stratification was applied, and geometric mean sdLDL-C levels for each age groups were calculated and plotted against gender.

For men, the level of sdLDL-C increased from $34.1 \mathrm{mg} / \mathrm{dL}$ in those $\nabla 39$ years to a maximum of $37.7 \mathrm{mg}$ / dL in those of 50-54 years, followed by decreasing from $36.4 \mathrm{mg} / \mathrm{dL}$ in those of 55-59 years to $27.4 \mathrm{mg} / \mathrm{dL}$ in those of $80 \leq$ years (Fig. 1). For women, a relatively regular increasing trend of the sdLDL$C$ level was found up to 60-64 year-olds. After 65 years, a downward trend was fitted. The maximum of the sdLDL-C level of women was $32.7 \mathrm{mg} / \mathrm{dL}$. Moreover, sdLDL-C levels in men were higher than those in women for all age groups younger than 70-74-year-olds but exceeded those in women after the age of 75-79 years.

\section{sdLDL-C/LDL-C ratio trends in 5-year age groups}

SdLDL-C/LDL-C ratio in men increased from 0.30 in 40-44-year-olds to a maximum of 0.35 in 50-54-yearolds, plateaued in those of 55-59 years, and then decreased from 0.34 in those of $60-64$ years to 0.28 in those of $80 \leq$ years (Fig. 2). For women, these values increased from 0.20 in those $<39$ years to a maximum of 0.28 in those of 65-69 years and plateaued after $70 \leq$ years (with mean levels of 0.27 ). SdLDL-C/LDL-C ratio in men was higher than those in women for all age groups and the crossover of sdLDL-C/LDL-C ratio for the genders did not occur.

Trends in other lipoproteins (LDL-C, total cholesterol, TG, HDL-C, and total cholesterol/HDL-C ratio) in 5year age groups

LDL-C level in men decreased almost linearly, while LDL-C level in women rapidly increased from $100.3 \mathrm{mg} / \mathrm{dL}$ in those aged < 39 years to a maximum of $132.8 \mathrm{mg} / \mathrm{dL}$ in 60-64-year-olds and decreased from $128.2 \mathrm{mg} / \mathrm{dL}$ in those aged $65-69$ to $119.5 \mathrm{mg} / \mathrm{dL}$ in those $80 \leq$ years (Fig. 3). The level of TC, nonHDL-C, and TC/HDL-C ratio revealed a pattern similar to the trend of LDL-C levels (Supplementary 
Fig. 1-3). The TG levels in men decreased almost linearly, while the level in women increased linearly (Supplementary Fig. 4). HDL-C in both men and women decreased almost linearly (Supplementary Fig. 5).

\section{SdLDL-C and sdLDL-C/LDL-C ratio in the standardized analysis among the three groups}

To standardize sdLDL-C and sdLDL-C/LDL-C ratio among the three groups and validate the abovementioned turning points, the participants were re-stratified by age ranges corresponding to increasing, plateau and decreasing phases for each marker by gender and multiple linear regression analysis was then applied.

As shown in Table 2, among men, age was positively and negatively associated with log-transformed small dense low-density lipoprotein cholesterol (LNsdLDL-C) levels in those $\leq 54$ years and $\geq 55$ years, with beta values of 0.006 and -0.010 , respectively. Among premenopausal women, postmenopausal women $\leq 64$ years, and postmenopausal women $65 \geq$ years, beta values of age were $0.014,0.014$ and, -0.004 , respectively. But the association between LNsdLDL-C and age was not significantly associated with men $\leq 54$ years. 
Table 2

Factors Associated with LN sdLDL-C Level in Age Groups by Gender

\begin{tabular}{|c|c|c|c|}
\hline Variable & $\beta$ & SE & $P$ \\
\hline \multicolumn{4}{|c|}{ Men $\leq 54, n=475 ;$ mean $\pm S D, 46.7 \pm 4.9$ years, Pearson's $r=0.320(P<0.001)$} \\
\hline Age & 0.006 & 0.004 & 0.169 \\
\hline BMI & 0.033 & 0.006 & $<0.001$ \\
\hline Fasting glucose & 0.004 & 0.002 & 0.003 \\
\hline \multicolumn{4}{|l|}{ Smoker } \\
\hline Current & 0.018 & 0.054 & 0.747 \\
\hline EX & 0.050 & 0.053 & 0.342 \\
\hline Drinker & 0.144 & 0.059 & 0.015 \\
\hline \multicolumn{4}{|c|}{ Men $\geq 55, n=1,922 ; 68.4 \pm 7.6$ years, Pearson's $r=0.316(P<0.001)$} \\
\hline Age & -0.010 & 0.001 & $<0.001$ \\
\hline BMI & 0.032 & 0.003 & $<0.001$ \\
\hline Fasting glucose & 0.002 & 0.001 & $<0.001$ \\
\hline \multicolumn{4}{|l|}{ Smoker } \\
\hline Current & 0.025 & 0.030 & 0.402 \\
\hline EX & 0.032 & 0.024 & 0.192 \\
\hline Drinker & 0.076 & 0.024 & 0.001 \\
\hline \multicolumn{4}{|c|}{ Women (Premenopausal), $n=517 ; 45.1 \pm 4.2$ years, Pearson's $r=0.330(P<0.001)$} \\
\hline Age & 0.014 & 0.005 & 0.002 \\
\hline BMI & 0.024 & 0.006 & $<0.001$ \\
\hline Fasting glucose & 0.008 & 0.002 & $<0.001$ \\
\hline \multicolumn{4}{|l|}{ Smoker } \\
\hline Current & 0.021 & 0.072 & 0.775 \\
\hline EX & -0.005 & 0.056 & 0.934 \\
\hline Drinker & 0.033 & 0.039 & 0.398 \\
\hline \multicolumn{4}{|c|}{ Women $\leq 64$ years (Postmenopausal), $n=978 ; 58.3 \pm 4.5$ years, Pearson's $r=0.261(P<0.001)$} \\
\hline $\begin{array}{l}\beta \text { is a coefficient } \\
\text { regression analy } \\
\text { lipoprotein chole }\end{array}$ & $\begin{array}{l}\text { rease in } \\
\text { LNsdLD } \\
\text { index. }\end{array}$ & $\begin{array}{l}\text { lent vari } \\
\text { רsforme }\end{array}$ & $\begin{array}{l}\text { ivariable linear logic } \\
\text { se low-density }\end{array}$ \\
\hline
\end{tabular}




\begin{tabular}{|c|c|c|c|}
\hline Variable & $\beta$ & SE & $P$ \\
\hline Age & 0.014 & 0.003 & $<0.001$ \\
\hline BMI & 0.019 & 0.004 & $<0.001$ \\
\hline Fasting glucose & 0.004 & 0.001 & $<0.001$ \\
\hline \multicolumn{4}{|l|}{ Smoker } \\
\hline Current & 0.052 & 0.067 & 0.437 \\
\hline EX & 0.036 & 0.051 & 0.479 \\
\hline Drinker & 0.007 & 0.026 & 0.792 \\
\hline \multicolumn{4}{|c|}{ Women $65 \geq$ years (Postmenopausal), $n=1,316 ; 72.6 \pm 5.7$ year olds, Pearson's $r=0.228(P<0.001)$} \\
\hline Age & -0.004 & 0.002 & 0.045 \\
\hline BMI & 0.022 & 0.004 & $<0.001$ \\
\hline Fasting glucose & 0.003 & 0.001 & 0.001 \\
\hline \multicolumn{4}{|l|}{ Smoker } \\
\hline Current & -0.086 & 0.078 & 0.267 \\
\hline EX & 0.204 & 0.076 & 0.007 \\
\hline Drinker & -0.007 & 0.024 & 0.760 \\
\hline
\end{tabular}

As shown in Table 3, the beta values of age for sdLDL-C/LDL-C ratio in men $\leq 54$ years, $55-59$ years, and $60 \geq$ years, were $0.003,0.004$, and -0.002 , respectively. In women, the beta values of age for sdLDLC/LDL-C ratio in premenopausal women, postmenopausal women $\leq 69$ years, and $70 \geq$ years were 0.001 , 0.002 , and 0.000 , respectively. The association between sdLDL-C/LDL-C and age was not significantly associated with men 55-59 years, premenopausal women, and postmenopausal women $70 \geq$ years. 
Table 3

Factors Associated with SdLDL-C/LDL-C Ratio in Age Groups by Gender

\begin{tabular}{|c|c|c|c|}
\hline Variable & $\beta$ & SE & $P$ \\
\hline \multicolumn{4}{|c|}{ Men $\leq 54$ years, $n=475$; mean $\pm S D, 46.7 \pm 4.9$ year olds, Pearson's $r=0.320(P<0.001)$} \\
\hline Age & 0.003 & 0.001 & 0.020 \\
\hline BMI & 0.005 & 0.002 & 0.012 \\
\hline Fasting glucose & 0.001 & 0.000 & 0.010 \\
\hline \multicolumn{4}{|l|}{ Smoker } \\
\hline Current & 0.029 & 0.016 & 0.081 \\
\hline EX & 0.011 & 0.016 & 0.501 \\
\hline Drinker & 0.049 & 0.018 & 0.007 \\
\hline \multicolumn{4}{|c|}{ Men $55-59$ years, $n=245 ; 57.2 \pm 1.4$ years, Pearson's $r=0.222(P<0.001)$} \\
\hline Age & 0.004 & 0.007 & 0.589 \\
\hline BMI & 0.003 & 0.003 & 0.385 \\
\hline Fasting glucose & 0.001 & 0.001 & 0.285 \\
\hline \multicolumn{4}{|l|}{ Smoker } \\
\hline Current & 0.049 & 0.032 & 0.125 \\
\hline EX & 0.062 & 0.030 & 0.042 \\
\hline Drinker & 0.055 & 0.027 & 0.041 \\
\hline \multicolumn{4}{|c|}{ Men $60 \geq$ years, $n=1,677 ; 70.0 \pm 6.8$ years, Pearson's $r=0.272(P<0.001)$} \\
\hline Age & -0.002 & 0.000 & $<0.001$ \\
\hline BMI & 0.005 & 0.001 & $<0.001$ \\
\hline Fasting glucose & 0.001 & 0.000 & $<0.001$ \\
\hline \multicolumn{4}{|l|}{ Smoker } \\
\hline Current & 0.029 & 0.009 & 0.001 \\
\hline EX & 0.009 & 0.007 & 0.235 \\
\hline Drinker & 0.055 & 0.007 & $<0.001$ \\
\hline \multicolumn{4}{|c|}{ Women (Premenopausal), $n=517 ; 45.1 \pm 4.2$ years, Pearson's $r=0.313(P<0.001)$} \\
\hline $\begin{array}{l}\beta \text { is a coefficient } i \\
\text { regression analys } \\
\text { LDL-C = low-dens }\end{array}$ & $\begin{array}{l}\text { rease in } \\
\text { sdLDL-( } \\
\text { ol; BMI }\end{array}$ & $\begin{array}{l}\text { ent vari } \\
\text { se low-c } \\
\text { ndex. }\end{array}$ & $\begin{array}{l}\text { ivariable linear logic } \\
\text { rotein cholesterol; }\end{array}$ \\
\hline
\end{tabular}




\begin{tabular}{|c|c|c|c|}
\hline Variable & $\beta$ & SE & $P$ \\
\hline Age & 0.001 & 0.001 & 0.147 \\
\hline BMI & 0.003 & 0.001 & 0.002 \\
\hline Fasting glucose & 0.001 & 0.000 & $<0.001$ \\
\hline \multicolumn{4}{|l|}{ Smoker } \\
\hline Current & 0.010 & 0.012 & 0.413 \\
\hline EX & 0.000 & 0.010 & 0.988 \\
\hline Drinker & 0.015 & 0.007 & 0.027 \\
\hline \multicolumn{4}{|c|}{ Women $\leq 69$ years (Postmenopausal), $n=1,434 ; 61.0 \pm 5.5$ years, Pearson's $r=0.264(P<0.001)$} \\
\hline Age & 0.002 & 0.000 & $<0.001$ \\
\hline BMI & 0.004 & 0.001 & $<0.001$ \\
\hline Fasting glucose & 0.001 & 0.000 & $<0.001$ \\
\hline \multicolumn{4}{|l|}{ Smoker } \\
\hline Current & 0.001 & 0.012 & 0.914 \\
\hline EX & 0.013 & 0.010 & 0.201 \\
\hline Drinker & 0.003 & 0.005 & 0.555 \\
\hline \multicolumn{4}{|c|}{ Women $70 \geq$ years (Postmenopausal), $n=860 ; 75.6 \pm 4.6$ year olds, Pearson's $r=0.167(P<0.001)$} \\
\hline Age & 0.000 & 0.001 & 0.704 \\
\hline BMI & 0.004 & 0.001 & $<0.001$ \\
\hline Fasting glucose & 0.001 & 0.000 & $<0.001$ \\
\hline \multicolumn{4}{|l|}{ Smoker } \\
\hline Current & -0.049 & 0.025 & 0.052 \\
\hline EX & 0.034 & 0.021 & 0102 \\
\hline Drinker & -0.004 & 0.006 & 0.501 \\
\hline $\begin{array}{l}\beta \text { is a coefficient } \\
\text { regression analys } \\
\text { LDL-C = low-dens }\end{array}$ & $\begin{array}{l}\text { ease in } \\
\text { dLDL-C }\end{array}$ & $\begin{array}{l}\text { ent varic } \\
\text { se low-d } \\
\text { index. }\end{array}$ & $\begin{array}{l}\text { ivariable linear logi } \\
\text { rotein cholesterol; }\end{array}$ \\
\hline
\end{tabular}

Considering the beta value of each variable, 50-year old standardized sdLDL-C levels in men, premenopausal women, and postmenopausal women were $26.6 \mathrm{mg} / \mathrm{dL}(95 \% \mathrm{Cl} ; 26.4-26.9 \mathrm{mg} / \mathrm{dL})$, $22.7 \mathrm{mg} / \mathrm{dL}(95 \% \mathrm{Cl} ; 22.5-22.9 \mathrm{mg} / \mathrm{dL}$ ), and $27.4 \mathrm{mg} / \mathrm{dL}$ (95\% Cl; 27.3-27.5 mg/dL), respectively. 
Standardized sdLDL-C/LDL-C ratio in men, premenopausal women, and postmenopausal women were 0.242 (95\% Cl; 0.240-0.244), 0.154 (95\% Cl; 0.153-0.156), and 0.227 (95\% Cl; 0.224-0.230), respectively. These differences between premenopausal women and postmenopausal women were significant (Bonferroni analysis, $\mathrm{P}<0.001$ ).

\section{Discussion}

To the best of our knowledge, the present study is the first to demonstrate the effects of age, gender, and menopausal status on the sdLDL-C and sdLDL-C/LDL-C ratio. The age-related sdLDL-C trends showed roughly an increasing phase, followed by a decreasing phase in men and a plateaued phase in middleaged women. The age-related sdLDL-C trend in men, but not in women, was similar to traditional lipid cholesterol profiles. The reason for this gender difference might be related to the mechanism of hypertriglyceridemia in postmenopausal women, which induced small LDL particles. ${ }^{18-20}$ There were age or gender-related differences in the ability to generate sdLDL-C from LDL-C. This ability in men was higher than that in women for all age groups or standardized groups, which is identical to the fact that atherosclerosis is more common in men than in women, considering sdLDL-C is a highly atherogenic factor.

Our study showed three important results. First, age showed partial correlation trends with sdLDL-C levels and sdLDL-C/LDL-C ratio and non-linear trends between age and sdLDL-C and sdLDL-C/LDL-C ratio were found in both men and women. Therefore, using the sdLDL-C and sdLDL-C/LDL-C ratio, the definition of CVD risk assessment and the adaption of the lipid-lowering therapy should fully consider age-related trends and gender differences.

Second, menopausal status was an additional determinant of increasing sdLDL-C and sdLDL-C/LDL-C ratio. SdLDLs are regulated through multiple and complex mechanisms regarding excess adiposity, free fatty acids, apo-lipoproteins, and action of lipoprotein lipase activity and cholesterol ester transfer protein for lipoproteins. ${ }^{12,16,17}$ In postmenopausal women, the decrease of plasma estrogen levels plays a significant role in reducing the clearance of LDL particles via LDL receptor and increasing TG and the number of smaller LDL particles. ${ }^{21}$ This hormone change was related to the process of regulating sdLDL$\mathrm{C}$ but there was little evidence available on the association between menopausal status and sdLDL-C or sdLDL-C/LDL-C ratio in a real-world, population setting. ${ }^{22}$ Our results showed that sdLDL-C in postmenopausal women was 0.8 or $3.9 \mathrm{mg} / \mathrm{dL}$ higher than men or premenopausal women in the standardized analysis.

Finally, the relationships between age-related trends in sdLDL-C and sdLDL-C/LDL-C ratio and gender were different from traditional lipid factors, such as LDL-C. The crossover of LDL-C for the genders occurred in middle-aged patients. On the contrary, the crossover of sdLDL-C occurred between 7074 years and the sdLDL-C/LDL-C ratio did not occur. Rather than LDL-C, the results of the sdLDL-C and sdLDL-C/LDL-C ratio might reflect the fact that, for all age groups, men have more susceptible to CVD than women, even with the narrowing gap of risk for CVD in postmenopausal women. ${ }^{23}$ 
Our findings suggest that a subgroup-specific approach is required to develop efficient cardiovascular disease prevention strategies using the sdLDL-C and sdLDL-C/LDL-C ratio.

\section{Limitations}

Our study has several limitations. First, age-related trends and levels of traditional lipid factors were almost similar to National Health and Nutrition Survey in Japan and our age-related trends of these factors were also similar to the trends of the Korean and Chinese Singaporeans population. ${ }^{14,15}$ But the trends of the US population or healthy Caucasian ${ }^{24,25}$ were not similar. Especially in healthy Caucasian patients aged $\geq 70$ years, the trends for TC, LDL-C, and nonHDL-C differed from our observed trends and continuously increased. Although our results could not identify the mechanism, there might be racial differences. Therefore, it is unclear whether our results of sdLDL-C would be valid for these populations. Second, compared with mean lipid levels of the Korean population from KNHANES, Japanese men showed higher mean TC, LDL-C, and HDL levels (TC 199 mg / dL; LDL-C 115 mg / dL; HDL-C 56 mg / dL) compared to Korean men (TC 183 mg / dL; LDL-C 106 mg / dL; HDL 50 mg / dL), and Japanese women also showed higher mean levels (TC 212 mg / dL; LDL-C 124 mg / dL; HDL-C 64 mg / dL) than Korean women (TC $188 \mathrm{mg} / \mathrm{dL}$; LDL-C $111 \mathrm{mg} / \mathrm{dL} ; \mathrm{HDL}-\mathrm{C} 55 \mathrm{mg} / \mathrm{dL}$ ). The reason for the difference in the lipoprotein profile between Japanese and Korean populations might be due to genetics and environmental factors. It is also unknown whether these factors might affect sdLDL-C levels and sdLDLC/LDL-C ratio because sdLDLs are regulated through complex mechanisms. Third, we did not control for the effects of genetic factors, mental stress, diet, life activity, and socioeconomic status, which might be associated with changes in lipid metabolism. ${ }^{26,27,28}$

\section{Conclusion}

SdLDL-C and sdLDL-C/LDL-C ratio are differently distributed by age, gender, and menopausal status. Our findings suggest that a subgroup-specific approach is required to develop efficient CVD prevention strategies using the sdLDL-C and sdLDL-C/LDL-C ratio.

\section{Abbreviations}

sdLDL-C

small dense low-density lipoprotein cholesterol; CVD:cardiovascular disease; LDL-C:low-density lipoprotein cholesterol; TC:total cholesterol; LDL-C:low-density lipoprotein cholesterol; TGs:triglycerides; HDL-C:high-density lipoprotein cholesterol:nonHDL-C:non-high-density lipoprotein cholesterol; LNsdLDLC:log-transformed small dense low-density lipoprotein cholesterol; JMS:Jichi Medical School; ANOVA; analysis of variance

\section{Declarations}


The authors thank the public health doctors, nurses, and officers in Shimotsuke, Kakara, Sue, Omori, Kamiichi, Wara, Takasu, Onabi, Nakatsu, Yame, Miwa, Ueno, and Saji areas, Japan, for their help, support, and contributions.

\section{Ethics approval and consent to participate}

All procedures performed in studies involving human participants were in accordance with the ethical standards of the institutional and/or national research committee and with the 1964 Helsinki declaration and its later amendments or comparable ethical standards. All the participants included in the present study provided written informed consent prior to inclusion, and this study was approved by the Institutional Review Board of Jichi Medical School (Tochigi, Japan, IRB No. G09-39 [G17-64 revised]).

\section{Consent for publication}

All the participants included in the present study provided written informed consent for publication.

\section{Availability of data and materials}

The datasets generated during and/or analysed during the current study are available from the corresponding author on reasonable request.

\section{AUTHOR CONTRIBUTIONS}

All authors have participated in the research and designed the study; $\mathrm{TI}$ and SI performed the statistics analysis; TI contributed to the drafting of the manuscript. All authors read and approved the final manuscript.

\section{Competing interests}

The authors declare they have no conflict of interest with respect to this research study and paper.

\section{Funding}

This research was supported by the MEXT-Supported Program for the Strategic Research Foundation at Private Universities (S0901032); a Japanese Society for the Promotion of Science KAKENHI grant (No. 16K09141); a Grant-In-Aid from the Ministry of Health, Labour, and Welfare; Health and Labor Sciences and Japan Comprehensive Research on Cardiovascular and Lifestyle-Related Diseases grants (H26Junkankitou-[Seisaku]-Ippan-001 and H29-Junkankitou-Ippan-003; IRB No. G09-39 [G17-64 revised]); and Jichi Medical University Almuni Association Project Grant 2020.

\section{References}

1. Grundy SM, Stone NJ, Bailey AL, Beam C, Birtcher KK, Blumenthal RS, Braun LT, de Ferranti S, FaiellaTomma- sino J, Forman DE, Goldberg R, Heidenreich PA, Hlatky MA, Jones DW, Lloyd-Jones D, Lopez- 
Pajares N, Ndu- mele CE, Orringer CE, Peralta CA, Saseen JJ, Smith SC Jr, Sperling L, Virani SS, Yeboah J. 2018AHA/ACC/ AACVPR/AAPA/ABC/ACPM/ADA/AGS/APhA/ASPC/ NLA/PCNA Guideline on the Management of Blood Cholesterol. Circulation, 2019; 139: e1082-e1143.

2. Lawler PR, Akinkuolie AO, Harada P, Glynn RJ, Chasman DI, Ridker PM, Mora S. Residual Risk of Athero- sclerotic Cardiovascular Events in Relation to Reductions in Very-Low-Density Lipoproteins. J Am Heart Assoc. 2017;6:1-11.

3. Varbo A, Nordestgaard BG. Remnant Cholesterol and Triglyceride-Rich Lipoproteins in Atherosclerosis Progres- sion and Cardiovascular Disease. Arterioscler Thromb Vasc Biol. 2016;36:2133-5.

4. Ivanova EA, Myasoedova VA, Melnichenko AA, Grechko AV, Orekhov AN. Small Dense Low-Density Lipoprotein as Biomarker for Atherosclerotic Diseases. Oxidative Medicine and Cellular Longevity, 2017; 2017: 1273042.

5. Kathiresan S, Otvos JD, Sullivan LM, Keyes MJ, Schaefer EJ, Wilson PWF, D’Agostino RB, Vasan RS, Robins SJ. Increased Small Low-Density Lipoprotein Particle Number. Circulation. 2006;113:20-9.

6. Arai H, Kokubo Y, Watanabe M, Sawamura T, Ito Y, Minagawa A, Okamura T, Miyamato Y. Small dense low-density lipoproteins cholesterol can predict incident car- diovascular disease in an urban Japanese cohort: the Suita study. J Atheroscler Thromb. 2013;20:195-203.

7. Hoogeveen RC, Gaubatz JW, Sun W, Dodge RC, Crosby JR, Jiang J, Couper D, Virani SS, Kathiresan S. Boerwin- kle E, Ballantyne CM. Small Dense Low-Density Lipo- protein-Cholesterol Concentrations Predict Risk for Cor- onary Heart Disease. Arterioscler Thromb Vasc Biol. 2014;34:1069-77.

8. St-Pierre AC, Cantin B, Dagenais GR, Mauriège P, Ber- nard P-M, Després J-P, Lamarche B. Low-Density Lipoprotein Subfractions and the Long-Term Risk of Ischemic Heart Disease in Men. Arterioscler Thromb Vasc Biol. 2005;25:553-9.

9. Nishikura T, Koba S, Yokota Y, Hirano T, Tsunoda F, Shoji M, Hamazaki Y, Suzuki H, Itoh Y, Katagiri T, Kobayashi Y. Elevated small dense low-density lipoprotein cholesterol as a predictor for future cardiovascular events in patients with stable coronary artery disease. J Atheroscler Thromb. 2014;21(8):755-67.

10. Mogarekar MR, Kulkarni SK. Small Dense Low Density Lipoprotein Cholesterol, Paraoxonase 1 and Lipid Profile in Postmenopausal Women: Quality or Quantity? Arch Med Res. 2015 Oct;46(7):534-8.

11. Gentile M, Panico S, Mattiello A, Ubaldi S, lannuzzo G, De Michele M, lannuzzi A, Rubba P. Association between small dense LDL and early atherosclerosis in a sample of menopausal women. Clin Chim Acta. 2013;426:1-5.

12. Johnson AA, Stolzing A. The role of lipid metabolism in aging, lifespan regulation, and age-related disease. Aging Cell. 2019;18(6):e13048.

13. Toth MJ, Tchernof A. Lipid metabolism in the elderly. Eur J Clin Nutr. 2000;54(Suppl 3):121-5.

14. Park JH, Lee MH, Shim JS, Choi DP, Song BM, Lee SW, Choi H, Kim HC. Effects of age, sex, and menopausal status on blood cholesterol profile in the korean population. Korean Circ J. 2015 Mar;45(2):141-8. 
15. Goh VH, Tong TY, Mok HP, Said B. Differential impact of aging and gender on lipid and lipoprotein profiles in a cohort of healthy Chinese Singaporeans. Asian J Androl. 2007;9(6):787-94.

16. Qamar A, Khetarpal SA, Khera AV, Qasim A, Rader DJ, Reilly MP. Plasma apolipoprotein C-III levels, triglycer- ides, and coronary artery calcification in type 2 diabetics. Arterioscler Thromb Vasc Biol. 2015;35:1880-8.

17. Pechlaner R, Tsimikas S, Yin X, Willeit P, Baig F, Santer P, Oberhollenzer F, Egger G, Witztum JL, Alexander VJ, Willeit J, KiechI S, Mayr M. Very-Low-Density Lipopro- tein-Associated Apolipoproteins Predict Cardiovascular Events and Are Lowered by Inhibition of APOC-III. J Am Coll Cardiol. 2017;69:789-800.

18. Cho Y, Lee SG, Jee SH, Kim JH. Hypertriglyceridemia is a major factor associated with elevated levels of small dense LDL cholesterol in patients with metabolic syndrome. Ann Lab Med. 2015;35(6):58694.

19. Hayashi T, Koba S, Ito Y, Hirano T. Method for estimating high sdLDL-C by measuring triglyceride and apolipoprotein B levels. Lipids Health Dis. 2017 Jan 26;16(1):21.

20. Dayspring TD. Understanding hypertriglyceridemia in women: clinical impact and management with prescription omega-3-acid ethyl esters. Int J Womens Health. 2011 Mar 9;3:87-97.

21. Campos H, Walsh BW, Judge H, Sacks FM. Effect of estrogen on very low density lipoprotein and low density lipoprotein subclass metabolism in postmenopausal women. J Clin Endocrinol Metab. 1997 Dec;82(12):3955-63.

22. Carr MC, Kim KH, Zambon A, Mitchell ES, Woods NF, Casazza CP, Purnell JQ, Hokanson JE, Brunzell JD, Schwartz RS. Changes in LDL density across the menopausal transition. J Investig Med. 2000 Jul;48(4):245-50.

23. Bhatnagar $P$, Wickramasinghe $K$, Williams $J$, Rayner $M$, Townsend $N$. The epidemiology of cardiovascular disease in the UK 2014. Heart.;101(15):1182-9.

24. Anagnostis P, Stevenson JC, Crook D, Johnston DG, Godsland IF. Effects of menopause, gender and age on lipids and high-density lipoprotein cholesterol subfractions. Maturitas. 2015;81(1):62-8.

25. Schaefer EJ, Lamon-Fava S, Cohn SD, Schaefer MM, Ordovas JM, Castelli WP, Wilson PW.Effects of age, gender, and menopausal status on plasma low density lipoprotein cholesterol and apolipoprotein B levels in the Framingham Offspring Study. J Lipid Res.;35(5):779-92.

26. Tenk J, Mátrai P, Hegyi P, et al. Perceived stress correlates with visceral obesity and lipid parameters of the metabolic syndrome: a systematic review and meta-analysis. Psychoneuroendocrinology. 2018;95:63-73.

27. Slopen N, Goodman E, Koenen KC, Kubzansky LD. Socioeconomic and other social stressors and biomarkers of cardiometabolic risk in youth: a systematic review of less studied risk factors. PLoS One. 2013;8(5):e64418.

28. Garcia CK, Mues G, Liao Y, Hyatt T, Patil N, Cohen JC, Hobbs HH. Sequence diversity in genes of lipid metabolism. Genome Res. 2001 Jun;11(6):1043-52. 
Figures

SdLDL-C, mg/dL

45

Figure 1

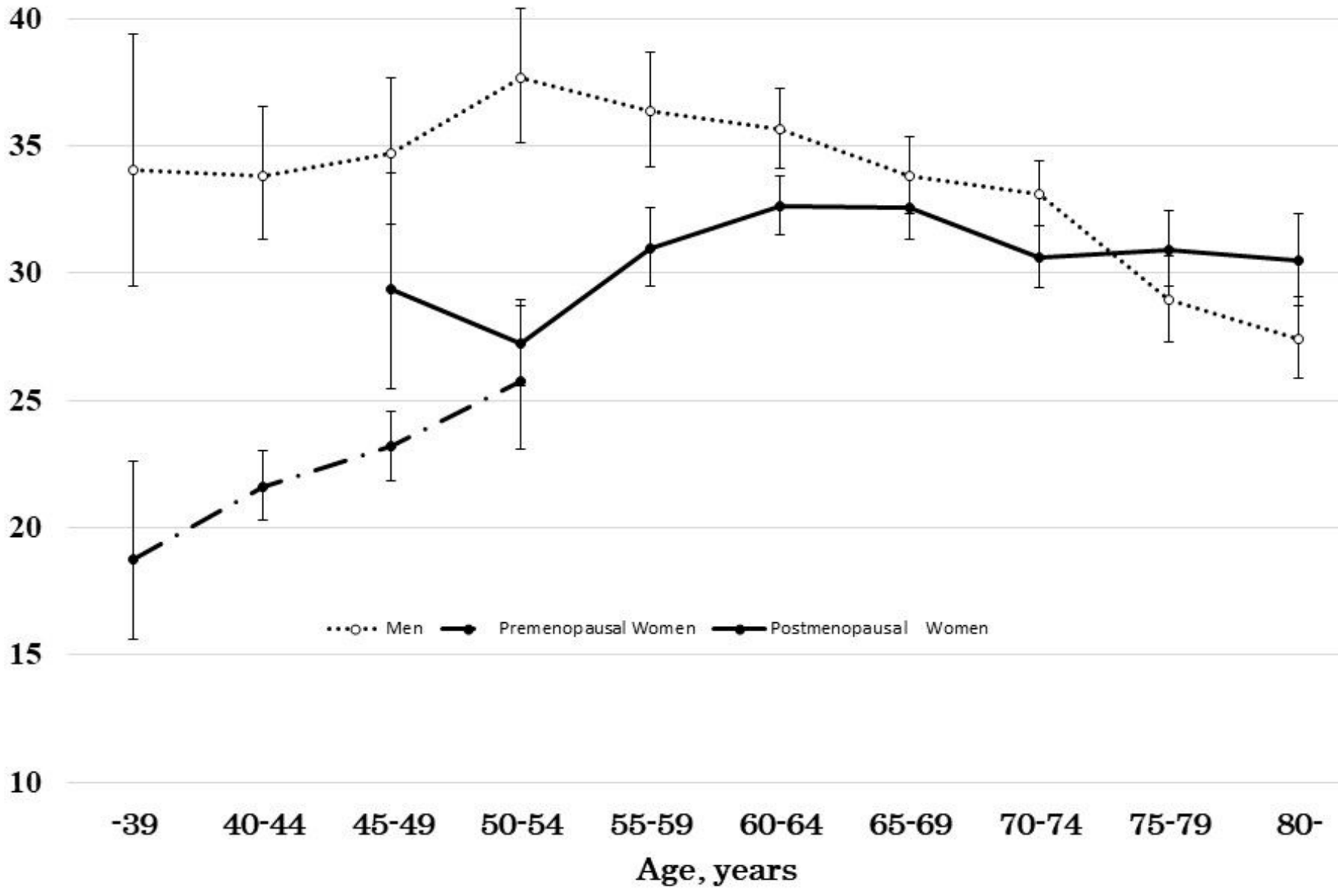

Figure 1

Geometric mean and $95 \%$ confidence interval of sdLDL-C for age, gender, and menopausal status 
0.4

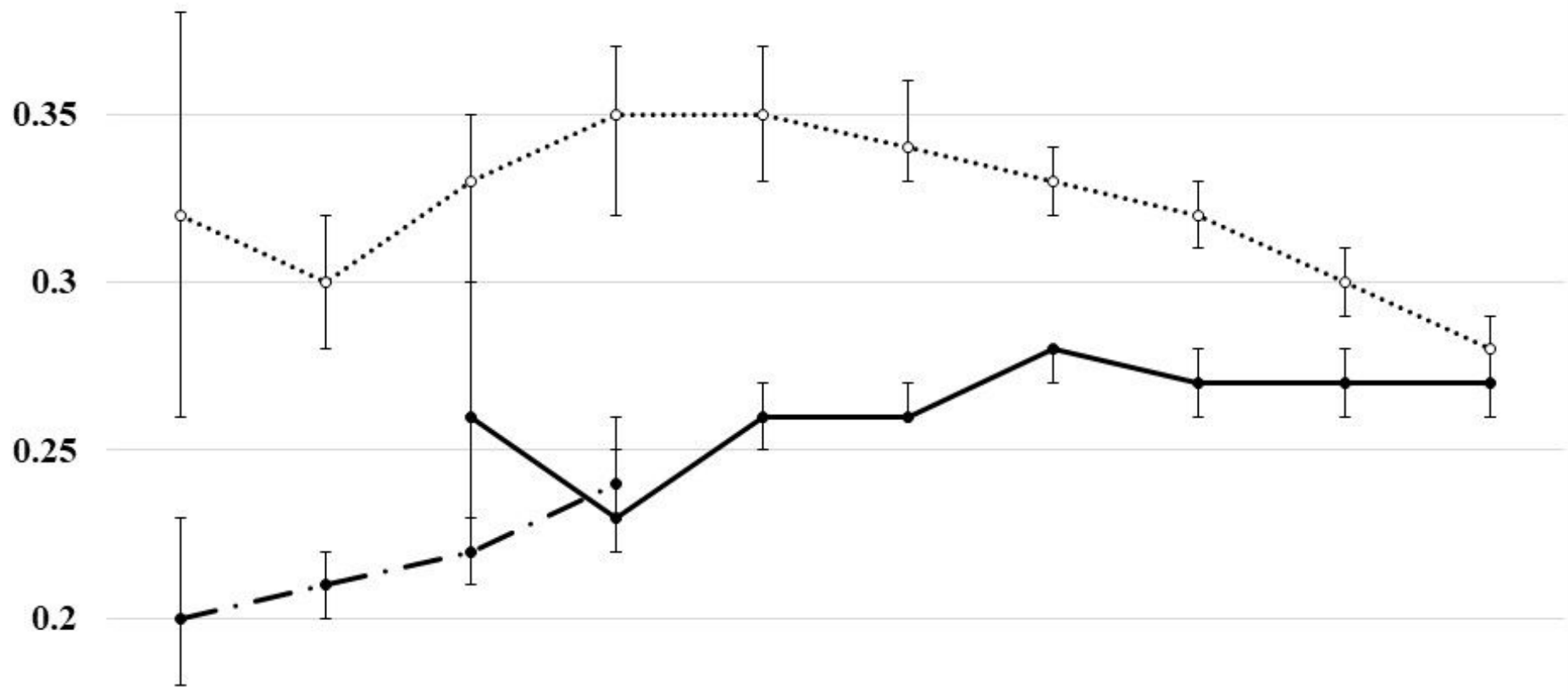

0.15

..... Men $\longrightarrow$ Premenopausal Women $\longrightarrow$ Postmenopausal Women

0.1

$\begin{array}{cccccccccc}<39 & 40-44 & 45-49 & 50-54 & \begin{array}{c}55-59 \\ \text { Age, years }\end{array} & 60-64 & 65-69 & 70-74 & 75-79 & 80-\end{array}$

Figure 2

Mean and $95 \%$ confidence interval of sdLDL-C/LDL-C ratio for age, gender, and menopausal status 


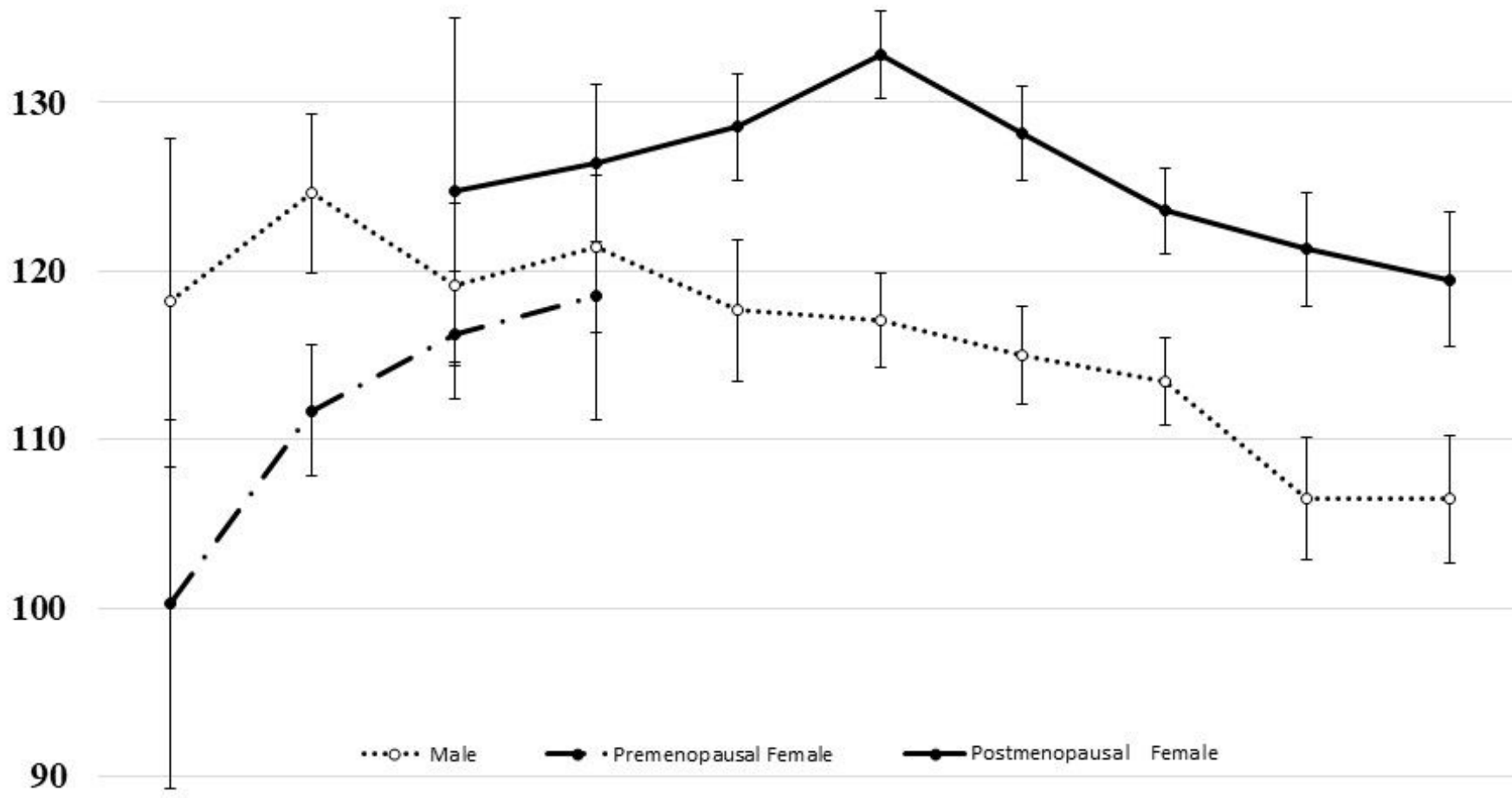

80

$\begin{array}{cccccccccc}-39 & 40-44 & 45-49 & 50-54 & 55-59 & 60-64 & 65-69 & 70-74 & 75-79 & 80- \\ \text { Age, years }\end{array}$

Figure 3

Mean and $95 \%$ confidence interval of LDL-C for age, gender, and menopausal status

\section{Supplementary Files}

This is a list of supplementary files associated with this preprint. Click to download.

- SFigure1.pptx

- SFigure1.pptx

- SFigure1.pptx

- SFigure2.pptx

- SFigure2.pptx

- SFigure2.pptx

- SFigure4.pptx 
- SFigure4.pptx

- SFigure4.pptx

- SFigure3.pptx

- SFigure3.pptx

- SFigure3.pptx

- SFigure5.pptx

- SFigure5.pptx

- SFigure5.pptx 